\title{
BAYESIAN PROBABILITIES FOR OCCURRENCE OF LARGE EARTHQUAKES IN THE SEISMOGENIC SOURCES OF JAPAN AND PHILLIPINE DURING THE PERIOD 1998-2017 T.M. TSAPANOS ${ }^{1}$, O.CH. GALANIS ${ }^{1}$, S.D. MAVRIDOU ${ }^{1}$, AND M.P. HELMI ${ }^{1}$
}

\begin{abstract}
The Bayesian statistics is adopted in 11 seismic sources of Japan and 14 of Philippine in order to estimate the probabilities of occurrence of large future earthquakes, assuming that earthquakes occurrence follows the Poisson distribution. The Bayesian approach applied represents the probability that a certain cut-off magnitude (or larger) will exceed in a given time interval of 20 years, that is 1998-2017. This cut-off magnitude is chosen the one with $M=7.0$ or greater. In this case we can consider these obtained probabilities as a seismic hazard presentation. More over curves are produced which present the fluctuation of the seismic hazard between these seismic sources. These graphs of varying probability are useful either for engineering or other practical purposes.
\end{abstract}

\section{EYNOYH}



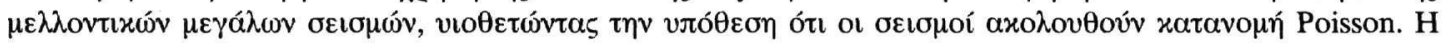

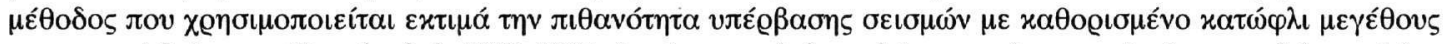

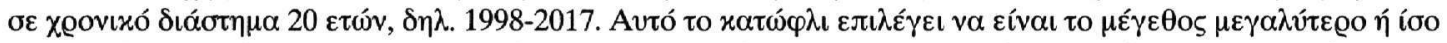



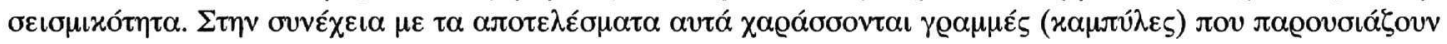



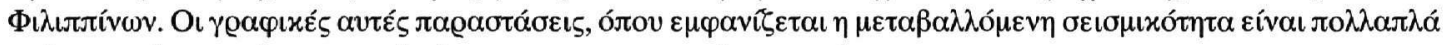

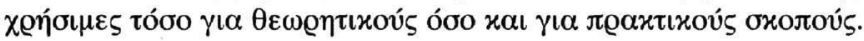

KEY WORDS: Bayesian probability, occurrence of earthquakes, seismic hazard curves, Japan, Phillipine.

\section{INTRODUCTION AND DATA USED}

Assuming the Poisson model Benjamin (1968) was the first who dealing with Baysian distribution for investigating the problem of earthquake occurrence. Mortgat and Shah (1979) presented a Bayesian model, for seismic hazard mapping, taking into account the geometry of the faults in the investigated area. Later Campbell (1982; 1983) suggested a Bayesian extreme value distribution of earthquake occurrence to asses the seismic hazard along San Jacinto fault. A probabilistic prediction of strong earthquakes in the main fracture zones of Greece is suggested by Stavrakakis and Tselentis (1987). They presented a seismic hazard curve which depicted the expected year of earthquake occurrence with $\mathrm{M}_{\mathrm{I}} \geq 5.5$ in the main fracture zones of Greece. The assessment of earthquake hazard parameters in Greece was presented by Papadopoulos and Kijko (1991), while recently Tsapanos (2000)estimated the seismic hazard parameters for various seismic regions in the circum-Pacific belt.

The main source for the present study is the catalogue compiled by Tsapanos et al. (1990). This catalogue is updated in order by taking into account the information up to 1997 from the bulletins of I.S.C. This final catalogue is modified by considering the magnitudes given by Pacheco and Sykes (1992). The seismic areas of Japan and Philippine are divided in seismogenic sources (Papazachos et. al., 1997)and we applied the method on these pre-defined seismogenic sources, although slightly modifications are considered.

\section{METHOD ESTIMATION OF THE PROBABILITIES}

The applied method is based on the assumption of a Poisson distribution for the number of events $n$, that occur in a time interval $t$. The probability function of the Poisson distribution is:

1. Aristotle University of Thessaloniki, School of Geology, Geophysical Laboratory, 54006 Thessaloniki, Greece. 


$$
P(n, t \backslash \lambda)=\frac{(\lambda t)^{n} e^{-\lambda t}}{n !}
$$

where the positive parameter 1 is the mean rate of earthquake occurrence.

Suppose that, in a given source, $n_{0}$ events occur and the time length of the catalogue is $t_{0}$ years. The likelihood function is:

$$
L(\lambda)=P\left(n_{0}, t_{0} \backslash \lambda\right)=\frac{\left(\lambda t_{0}\right)^{n_{0}} e^{-\lambda t_{0}}}{n_{0} !}
$$

It is well known that likelihood is the probability of the specific outcome to occur, that is the probability for exactly $n_{0}$ earthquakes to occur in $t_{0}$ years covered by the catalogue, as a function of the mean rate of occurrence of events. We can also assume that the prior distribution l, l'(l)is uniform. This is equivalent to stating that the mean rate of occurrence can have any value, as long as it is not negative, with the same probability. From the Bayesian theory its posterior distribution will be:

$$
f^{\prime \prime}(\lambda)=c f^{\prime}(\lambda) L(\lambda)
$$

where $c$ is a constant such that the resulting function can be a probability density function, that is:

$$
\int_{0}^{+\infty} f^{\prime \prime}(\lambda) d \lambda=1
$$

Because |'(l) is independent of $l$, the factor $k=c f^{\prime}(1)$ of equation (3) is constant, and the equation (4) is rewritten as:

$$
f^{\prime \prime}(\lambda)=k L(\lambda)=k \frac{\left(\lambda t_{o}\right)^{n_{o}} e^{-\lambda t_{o}}}{n_{o} !}
$$

This expression is normalized for $\mathrm{k}=t_{0}$. Lets now consider that the posterior probability of $n$ events occurring in $t$ years. This will be the probability $P(n, t \mid 1)$ weighted in respect to the posterior distribution of 1 :

$$
P^{\prime \prime}(E)=\int_{0}^{\infty} P(n, t \backslash \lambda) f^{\prime \prime}(\lambda) d \lambda=\int_{0}^{\infty} \frac{(\lambda t)^{n} e^{-\lambda t}}{n !} \frac{t_{0}\left(\lambda t_{0}\right)^{n_{0}} e^{-\lambda t_{0}}}{n_{0} !} d \lambda
$$

Integration yields by Benjamin (1968):

$$
P^{\prime \prime}(n, t)=\frac{\left.n+n_{0}\right) !}{n ! n_{0} !} \frac{\left(t / t_{0}\right)^{n}}{\left(1+t / t_{0}\right)^{n+n_{0}+1}}
$$

The posterior probability of no events occurring in $t$ years, comes from eqn.(7):

$$
P(0, t)=\left(1+t / t_{0}\right)^{-n_{0}-1}
$$

So we derived that the probability of exceedance of a given magnitude, that is the probability of at least one event occurring in $t$ years is:

$$
P(0, t)=1-\left(1+t / t_{0}\right)^{-n_{0}-1}
$$

which is the equation used to estimate the probabilities of exceedance of the magnitude 7.0 for the seismogenic sources of Japan and Philippine and for the next 20 years.

\section{RESULTS OF ANALYSIS}

It is well known that both examined areas (Japan and Philippine) considered as seismically active regions. Tsapanos and Burton (1991) ranked, Japan and Philippine, according to their seismic hazard in the first and the third place, respectively among fifty most active countries of the world.

A probabilistic analysis was carried out (Papaioannou, et al., 1993)in order to predict the probabilities of large future earthquakes in selected seismic zones of the world. This was based on the time dependent seismicity 
model and the results showed that both examined regions exhibited very high probability of occurrence of great earthquakes with $M \geq 8.0$ during the time period 1986-2006. Those very high probabilities were interpreted in terms of the dimensions of the considered seismic zones.

Now we dealt with seismogenic sources which are clearly much smaller in comparison with the whole seismic zones of Japan and Philippine. In Figure (1)the seismogenic sources and the earthquakes considered for the present study of: a)Japan and b)Philippine, are depicted. In Table (1) the name of the seismogenic sources, the number of mainshocks, $n_{0}$, with magnitude $M \geq 7.0$, the length of the catalogue used $t_{0}$, and the exceedance probability Prob for an earthquake occurrence with $M \geq 7.0$ in next 20 years (1998-2017) are listed. The time span of 20 years is adopted on the basis that probability computations are often more constant than they are for shorter time intervals. A first inspection in Table (1) reveals that the method is dependent on the number of events that generated in the past. This is because the prior distribution of the parameter 1 is uniform and consequently the posterior distribution dependents on the number of the observed earthquakes.

Table 1. The probabilities of exceedance of large earthquakes occurrence for magnitudes $M \geq 7.0$ in Japan and Philippine during the time period 1998-2017. The probability estimators are multiplied by 100.

$\begin{array}{cccc}\text { seismogenic source } & \underline{\mathbf{n}_{0}} & \underline{\mathbf{t}} & \underline{\text { Prob }(\%)} \\ \text { Japan 1 } & 4 & 103 & 58.8 \\ \text { Japan 2 } & 2 & 103 & 41.3 \\ \text { Japan 3 } & 22 & 103 & 98.3 \\ \text { Japan 4 } & 7 & 103 & 75.8 \\ \text { Japan 5 } & 6 & 103 & 71.1 \\ \text { Japan 6 } & 4 & 103 & 58.8 \\ \text { Japan 7 } & 6 & 103 & 71.1 \\ \text { Japan 8 } & 2 & 103 & 41.3 \\ \text { Japan 9 } & 6 & 103 & 71.1 \\ \text { Japan 10 } & 6 & 103 & 71.0 \\ \text { Japan 11 } & 4 & 103 & 58.8 \\ \text { Japan 12 } & 4 & 103 & 58.8 \\ \text { Philippine 1 } & 2 & 103 & 41.3 \\ \text { Philippine 2 } & 2 & 103 & 41.3 \\ \text { Philippine 3 } & 2 & 103 & 41.3 \\ \text { Philippine 4 } & 19 & 103 & 97.1 \\ \text { Philippine 5 } & 1 & 103 & 29.9 \\ \text { Philippine 6 } & 5 & 103 & 65.5 \\ \text { Philippine 7 } & 8 & 103 & 79.8 \\ \text { Philippine 8 } & 8 & 103 & 79.8 \\ \text { Philippine 9 } & 8 & 103 & 79.8 \\ \text { Philippine 10 } & 11 & 103 & 88.1 \\ \text { Philippine 11 } & 7 & 103 & 75.8 \\ \text { Philippine 12 } & 13 & 103 & 92.7 \\ \text { Philippine 13 } & 2 & 103 & 41.3 \\ \text { Philippine 14 } & 8 & 103 & 79.8\end{array}$

We observe (Table 1) that the largest probability (98\%)is estimated for the 3rd seismogenic source of Japan. All the other sources show probabilities of occurrence less than or equal to $75 \%$. We also observe that 3 seismogenic sources of Philippine show very high probabilities of occurrence of great earthquakes during the time period 1998-2017. These are the sources $4(97 \%), 10(88 \%)$ and $12(92 \%)$. Next we apply the time dependent seismicity model in order to check the validity of the data obtained through Bayes statistics. For computing the probability, $P$, that the repeat time $T$ of an earthquake of certain magnitude interval will occur in a seismogenic source during the next Dt years, conditional to the t years that have elapsed since the last earthquake of this magnitude in this source we applied the following formula:

$$
P(t \leq T<t+\Delta t / T>t)=\frac{\int_{t}^{t+\Delta t} n(t) d t}{\int_{t}^{\infty} n(t) d t}
$$




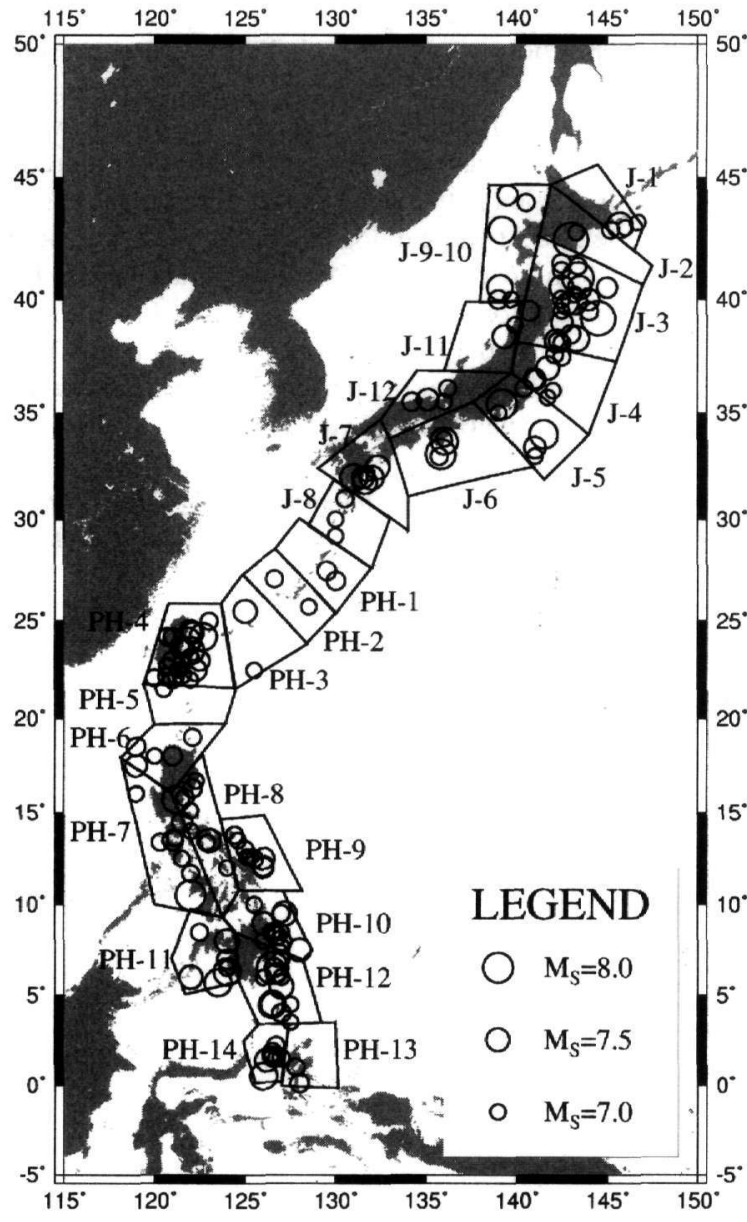

Fig. 1. The seismogenic sources and the epicenters of the shallow earthquakes ( $\mathrm{h} \leq 60 \mathrm{~km}$ ) with the magnitude $\mathrm{Ms}=7.0$ in the areas of japan and Philippine.

if we assume that the Gaussian distribution of repeat times is the appropriate one and is given through the equation:

$$
n(t)=\frac{1}{\sigma \sqrt{2 \pi}} \exp \left[-\frac{1}{2}\left(\frac{t-T_{m}}{\sigma}\right)\right]
$$

where $s$ is the standard deviation (Nishenko,1985; Papazachos, et al.,1987). The uncertainties of estimates play a key role to the procedure and we have to give proper attention to their determination.

So the probabilities based on the time dependent model are estimated equal to $98.5 \%$ for the seismogenic source 3 of Japan, while for the seismogenic sources 4,10 and 12 of Philippine we obtained probabilities equal to $99.8 \%$ and $100 \%$ (both sources 10 and 12), respectively. These results show a great accordance to those obtained through Bayes approach. The lowest probability $(29.9 \%)$ for all the examined sources is estimated for the seismogenic source 5 of Philippine. We divided the seismogenic sources in 4 categories. In those having very high probability values $(\geq 80 \%)$, in those of high probability ( $\geq 60 \%$ and $\leq 79 \%)$, in those of medium probability $(\geq 40 \%$ and $\leq 59 \%$ ) and those of low probability ( $\leq 39 \%)$. In Figure (2)we present a probabilistic map based on the above division. It is presents the probability that a certain source will be the place of a future earthquake with $M \geq 7.0$ during the time period 1998-2017.

The geographical distribution of the obtained Bayes probabilities are illustrated in Figure 3 (a and b). This is dine by plotting the probabilities of exceedance as a function of the source number for Japan (fig. 3a) and Philippine (fig. $3 \mathrm{~b}$ )for the time period of 20 years. This can consider as a hazard curve and is very useful because identify sources of special interest of earthquake occurrence. 


\section{DISCUSSION AND CONCLUSIONS}

Japan and Philippine are two areas of high seismicity and often both experienced of catastrophic earthquakes. For this reason the Bayesian probabilities for occurrence of large earthquakes (with $\mathrm{M} \geq 7.0$ )in the seismogenic sources of these areas during the time period 1998-2017 are estimated. The time span of 20 years is adopted on the basis that probability computations are often more constant than they are for shorter time intervals. Very high probabilities ( $\geq 80 \%$ ) are estimated for the seismogenic sources of Japan (3), as well as of Philippine (4,10 and 12). The probabilities for these sources of special interest are also computed by the application of the time dependent model of seismicity, which is based on the time lapse since the last earthquake of this magnitude $(M \geq 7.0)$. The obtained results are in very good agreement with the ones computed by Bayes statistics which is a rather Poissonian approach. We have to give special interest in the results of seismogenic source 4 of Philippine. Both Bayes statistics and the time dependent model show very high probabilities, $97.1 \%$ and $99.8 \%$, respectively for earthquake occurrence $(M \geq 7.0)$ during the time span 1998-2017, given that the year of the last occurrence of such earthquake magnitude was in 1986. The mean repeat time is estimated about 11 years. During September 1999 a catastrophic event with magnitude $\mathrm{M}_{\mathrm{s}}=7.4$ (N.E.I.C.-bulletins) occurred within this source. So we can conclude that our results are reliable and came true by the genesis of this earthquake. A map with well defined zones of probabilities for great earthquake occurrence in Japan and Philippine sources during 1998-2017 is given.

We also present hazard curves as a function of the Bayes probabilities of the examined seismogenic sources. This plot gives the ability of direct comparisons, in which source the hazard is higher or lesser during the time period 1998-2017. This lead to the conclusion that these plots of varying probability are very useful allowing the designation of priority sources for earthquake-resistant design.

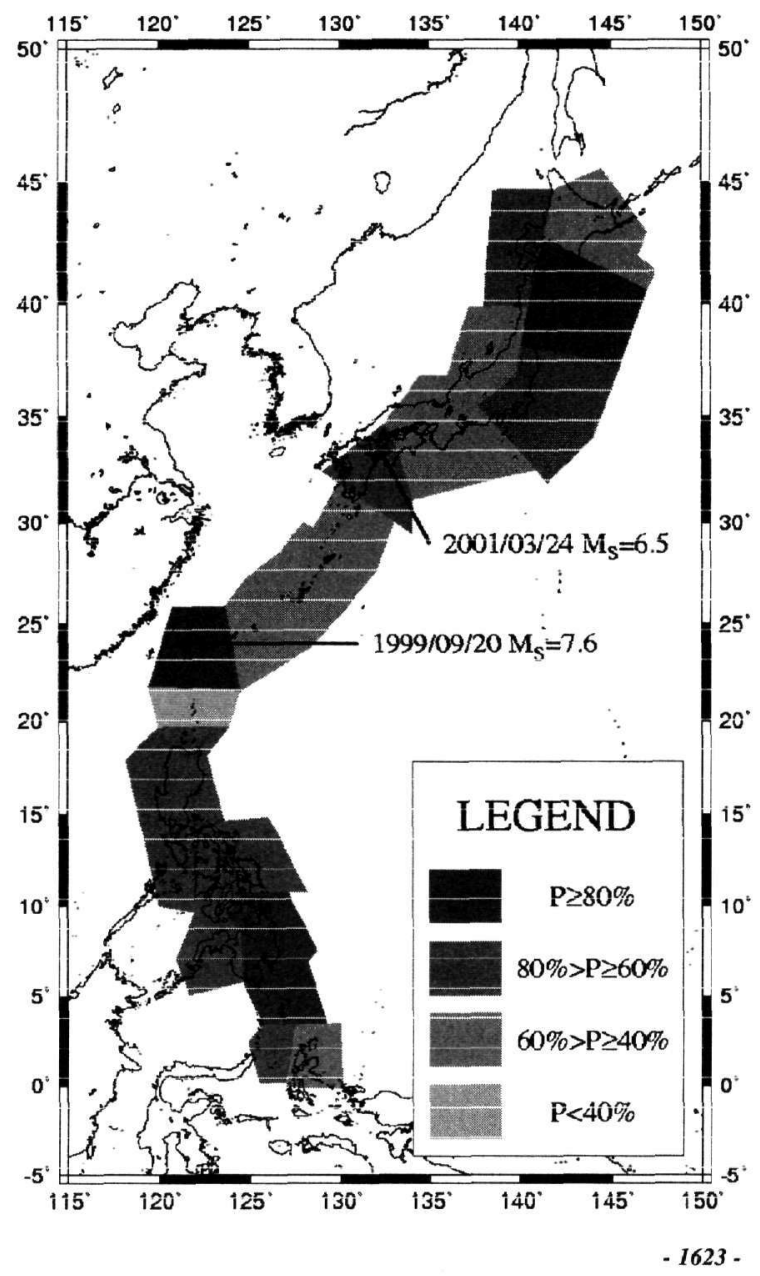

Fig. 2. Probability map of the occurrence of shallow earthquakes with $M_{s}{ }^{37.0}$ during the period 1998-2017 in the areas of Japan and Philippine. Four probability intervals are considered. Black arrows indicate the epicenters of the earthquakes a) $M_{S}=7.6$ which occurred in September of 1999 in Taiwan (Philippine-source 4) and the probability of this source is estimated $97.1 \%$ through Bayes statistics and 98.5 by the timedependent model; and b) $M_{s}=6.5$ which occurred in March of 2001 in Japan (source 7). The probability for this source is estimated $71.1 \%$ by Bayes statistics, while the timedependent model yields $80.5 \%$. 

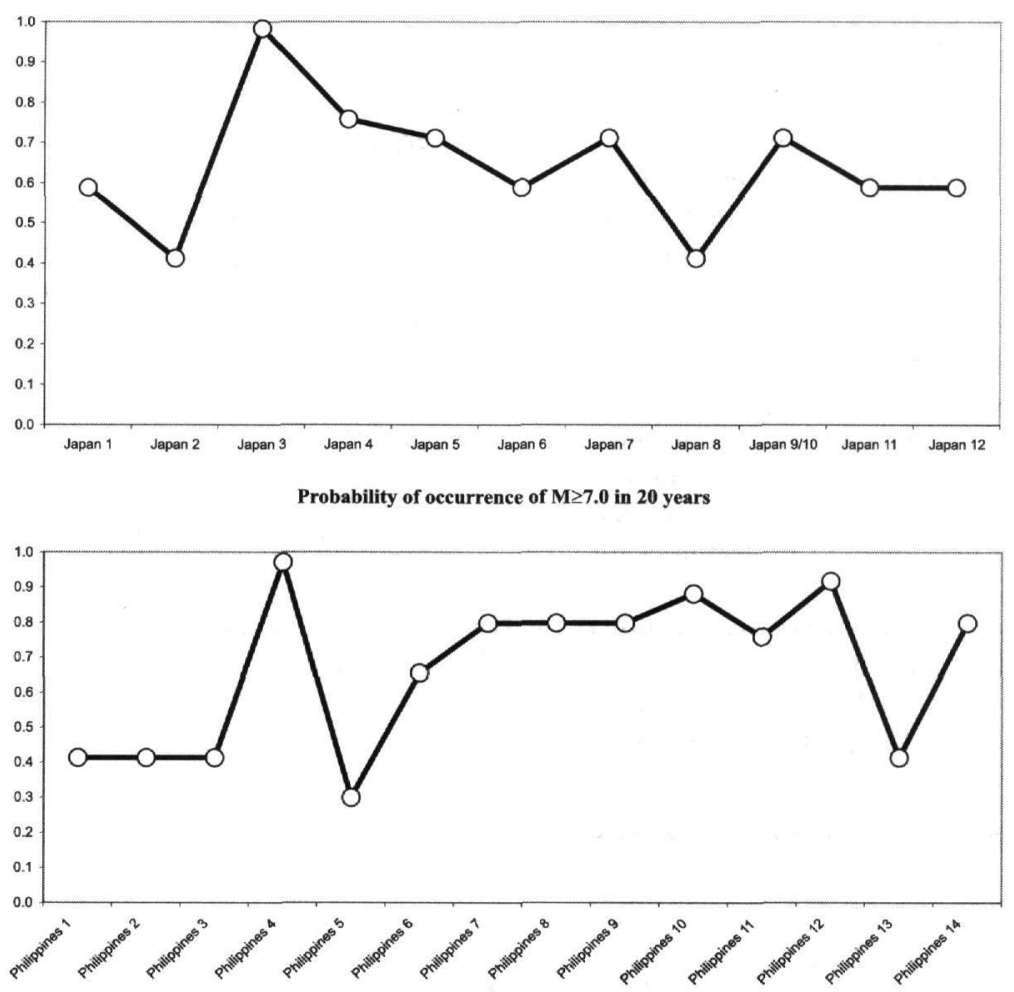

Fig. 3. Geographical distribution of probability of excedance of magnitude 7.0 in: a) japan and b) Philippine.

\section{REFERENCES}

BENJAMIN, J.R.(1968). Probabilistic models for seismmic force design, J. Struct. Div., ASCE, 94(ST5), 117-1196.

CAMPBELL, K.W. (1982). Bayesian analysis of extreme earthquake occurrences. Part I. Probabilistic hazard model, Bull. Seismol. Soc. Am., 72, 1689-1705.

CAMPBELL, K.W. (1983). Bayesian analysis of extreme earthquake occurrences. Part II. Application to the San Jacinto fault zone of California, Bull. Seismol. Soc. Am., 73, 1099-1115.

MORTGAT, C.P.. and SHAH, H.C. (1979). A Bayesian model for seismic hazard mapping, Bull. Seismol. Soc. Am., 69, $1237-1979$.

NISHENKO, S.P. (1985). Seismic potential for large and great interplate earthquakes along the Chilean and southern Perouvian margins of south America: a quantitative reappraisal, J. Geophys. Res., 90, 3589-3615.

PACHECO, J.F. and SYKES, L.R. (1992). Seismic moment catalog of large shallow earthquakes, 1900 to 1989, Bull. Seismol. Soc. Am., $82,1306-1349$

PAPADOPOULOS, G.A. and KIJKO, A.,(1991). Maximum likelihood estimation of earthquake hazard parameters in the Aegean area from mixed data, Tectonophysics, 185, 277-294.

PAPAIOANNOU, CH.A., TSAPANOS, T.M. SCORDILIS, E.M. and PAPAZACHOS, B.C., (1993). Probabilities of occurrence of large earthquakes in very active zones of the Earth, Bull. Geol. Soc. Greece, XXVIII/3, 171-179.

PAPAZACHOS, B.C., PAPADIMITRIOU, E.E., KIRATZI, A.A., PAPAIOANNOU, Ch. A. and KARAKAISIS, G.E. (1987). Probabilities of occurrence of large earthquake in the Aegean and surrounding area during the period 1986-2006, Pageoph, 125, 597-612.

PAPAZACHOS, B.C, PAPADIMITRIOU, E.E, KARAKAISIS, G.F. and PANAGIOTOPOULOS, D.G. (1997). Long-term Earthquake prediction in the circum-Pacific convergent belt, Pageoph, 149, 173-217.

STAVRAKAKIS, G.N. and TSELENTIS, G.A. (1987). Bayesian probabilistic prediction of strong earthquakes in the main seismogenic zones of Greece, Boll. Geofis. Teor. Appl., XXIX, 51-63.

TSAPANOS, T.M. (2000). Evaluation of the seismic hazard parameters for selected regions of the world: The maximum regional magnitude, Ann. di Geofis., (in press).

TSAPANOS, T.M. and BURTON P.W. (1991). Seismic hazard evaluation for specific seismic regions of the world, Tectonophysics, 195, 153-169.

TSAPANOS, T.M., SCORDILIS, E.M., and PAPAZACHOS, B.C. (1990). A global catalogue of strong earthquakes, Publ. Geophys. Lab. Univ. Thessaloniki, Thessaloniki, 9, 90pp. 